NBER WORKING PAPER SERIES

WORK INCENTIVES IN THE SOCIAL SECURITY DISABILITY BENEFIT FORMULA

Gopi Shah Goda

John B. Shoven

Sita Slavov

Working Paper 21708

http://www.nber.org/papers/w21708

\author{
NATIONAL BUREAU OF ECONOMIC RESEARCH \\ 1050 Massachusetts Avenue \\ Cambridge, MA 02138 \\ November 2015
}

This research was supported by the Mercatus Center at George Mason University. The findings and conclusions expressed are solely those of the authors. The views expressed herein are those of the authors and do not necessarily reflect the views of the National Bureau of Economic Research.

NBER working papers are circulated for discussion and comment purposes. They have not been peerreviewed or been subject to the review by the NBER Board of Directors that accompanies official NBER publications.

(C) 2015 by Gopi Shah Goda, John B. Shoven, and Sita Slavov. All rights reserved. Short sections of text, not to exceed two paragraphs, may be quoted without explicit permission provided that full credit, including $(\subset$ notice, is given to the source. 
Work Incentives in the Social Security Disability Benefit Formula

Gopi Shah Goda, John B. Shoven, and Sita Slavov

NBER Working Paper No. 21708

November 2015

JEL No. H31,H53,J22,J26

\begin{abstract}
$\underline{\text { ABSTRACT }}$
We examine the connection between taxes paid and benefits accrued under the Social Security Disability Insurance (SSDI) program on both the intensive and extensive margins. We perform these calculations for stylized workers given the existing benefit structure and disability hazard rates. On the intensive margin, we examine the effect of an additional dollar of earnings on the marginal payroll taxes contributed and future benefits earned. We find that the present discounted value of disability benefits received from an additional dollar of earnings, net of the SSDI payroll tax, generally declines with age, becoming negative around age 40 and reaching almost zero at age 63. On the extensive margin, we determine the effect of working an additional year on the additional payroll taxes and future benefits as a percentage of income. The return to working an additional year at an income level just large enough to earn Social Security credits for the year is large and positive through age 60. However, the return to working an additional full year is substantially smaller and becomes negative at approximately age 57 . Thus, older workers face strong incentives to earn enough to obtain creditable coverage through age 60, but they face disincentives for additional earnings. In addition, workers ages 61 and older face work disincentives at any level of earnings. We repeat this analysis for stylized workers at different levels of earnings and find that, while the program transfers resources from high earners to low earners, the workers experience similar patterns in the returns to working.
\end{abstract}

\author{
Gopi Shah Goda \\ Stanford University \\ SIEPR \\ 366 Galvez St. \\ Stanford, CA 94305 \\ and NBER \\ gopi@stanford.edu \\ John B. Shoven \\ Department of Economics \\ 579 Serra Mall at Galvez Street \\ Stanford, CA 94305-6015 \\ and NBER \\ shoven@stanford.edu
}

\author{
Sita Slavov \\ School of Policy, Government and \\ International Affairs \\ George Mason University \\ 3351 Fairfax Drive \\ Arlington, VA 22201 \\ and NBER \\ sslavov@gmu.edu
}




\title{
Work Incentives in the Social Security Disability Benefit Formula
}

\author{
Gopi Shah Goda, John B. Shoven, and Sita Nataraj Slavov
}

\section{Introduction}

The Social Security Disability Insurance (SSDI) program received approximately $\$ 111$ billion in payroll tax contributions and paid approximately $\$ 140$ billion in benefit payments in 2013 (Social Security Administration 2014b, Table 4. A2). According to projections, the SSDI trust fund will be depleted in 2016, and the program will no longer be able to pay benefits as scheduled. The economic efficiency of the program depends heavily on several factors, including, for instance, the relationship between economic conditions and benefit applications and awards and the capacity of SSDI recipients to continue working (Autor and Duggan 2003; Maestas, Mullen, and Strand 2013). In this paper, we examine another aspect of the efficiency of the program, namely the labor supply incentives for healthy individuals that arise from the tax and benefit structure on both the intensive and extensive margins. To the extent that contributions toward payroll taxes differ from the present discounted value of expected benefits earned by those contributions, the SSDI portion of payroll taxes (equal to 1.8 percent of earnings) may create work incentives or disincentives. Work incentives could arise if the additional benefits earned from additional payroll taxes paid are larger than the payroll taxes paid, and disincentives could result from little or no additional benefits earned from additional contributions. ${ }^{1}$

We use stylized earnings histories and population disability hazard rates to illustrate the work incentives from an additional dollar earned each year during one's career and from

\footnotetext{
${ }^{1}$ Our estimates of the expected present value of SSDI likely understate the value of the program to risk-averse individuals, who benefit from the insurance aspect of the program.
} 
participating in the labor force for an additional year as measured by the expected value of additional SSDI benefits from additional earnings. The first exercise sheds light on the work incentives on the intensive margin of earning additional income, while the second informs those incentives on the extensive margin of working an additional year. We find that in work years that contribute to the SSDI benefit calculation, the increase in the expected present discounted value of disability benefits from an additional dollar of earnings generally declines with age. Specifically, the return to earning additional income for average earners is positive until ages 42 for women and 38 for men; after this, the return becomes negative. This pattern emerges because the probability of becoming disabled at some point before retirement age is higher when more years are remaining until retirement, and increasing one's earnings at younger ages increases one's potential benefit paid over a longer horizon. ${ }^{2}$

On the extensive margin, a different pattern emerges. The eligibility requirements to qualify for disability benefits stipulate that an individual must have worked five of the most recent ten years. Thus, for an individual who has worked continuously, extending his or her career by one year is equivalent to purchasing a one-year term disability insurance policy five years into the future. The value of this policy depends on the probability of becoming disabled during that year, the annual benefit amount that would be paid, and the length of the benefit period over which the benefit would be paid. While the probability of becoming disabled increases with age, the length of time a person is expected to receive disability benefits declines.

\footnotetext{
${ }^{2}$ As a person ages, both retirement age and the end of life get closer. Disability benefits convert to retirement benefits at the normal retirement age. These retirement benefits are higher than the retirement benefits that a nondisabled person with an identical earnings history could collect at normal retirement age, as disabled individuals are not penalized for zero (or low) earnings during years of disability. Our calculations take into account this postretirement net increase in benefits because of disability insurance. However, the net benefit from disability insurance is clearly smaller once retirement benefits are available; after this point, SSDI simply boosts retirement benefits that could have been received even without disability insurance. Thus, the stream of income from disability insurance drops at normal retirement age and ends at death.
} 
Therefore, our results show that the expected present value of benefits from working an additional year is nonmonotonic, peaking at age 50 and then declining as the increase in expected benefits from the higher probability of being disabled is outweighed by the reduction in expected benefits from the shorter potential benefit horizon. We note, however, that the margin of permanently retiring from the labor force is not very relevant for workers under age 50 . For these workers, intensive margin work incentives are perhaps more relevant.

The size of the extensive margin benefit relative to the SSDI payroll tax depends on the amount of income earned during the additional year of work. On the one hand, if a worker earns the minimum required to extend eligibility under SSDI, the return on working an additional year is substantial, topping out at more than 35 percent of the additional earnings at age 50 and becoming negative only at age 61 . On the other hand, an additional full year of earnings provides a much more modest return net of the 1.8 percent payroll tax, topping out at less than 1.5 percent of earnings at age 50 and becoming negative by age 57 . This difference occurs because the extension of eligibility does not depend on the amount earned during the additional year of work. Thus, earning more than the minimum required to extend eligibility does not provide much additional benefit. The difference between the return to earning the minimum required to extend eligibility and the return to earning a higher salary reflects the relatively low returns to working on the intensive margin described earlier.

In either scenario, after one reaches age 62 , the value of the one-year term disability insurance policy five years into the future is zero. At this point, eligibility is already guaranteed through normal retirement age, and the one-year extension of the eligibility window occurs after normal retirement age. Thus individuals who become disabled during the additional year of eligibility are simply paid the retirement benefit to which they would be entitled anyway. 
Although earnings at ages 62-65 (if they are large enough) can still boost any disability benefits claimed before normal retirement age, this effect is small, and the 1.8 percent payroll tax is almost a pure tax on work at these higher ages.

We repeat this analysis for stylized workers at different levels of earnings. We assume that workers with higher levels of earnings have lower probabilities of becoming disabled, using differences in disability hazards by education as a proxy (von Wachter 2012). We find that the SSDI program provides high-earning individuals with lower returns from working on the intensive and extensive margins; this difference results from the group's lower disability hazards and higher levels of earnings combined with the progressive nature of the benefit formula. However, the patterns discussed here persist for all earnings groups.

This paper updates and corroborates the findings of Cushing (2005), who describes the work incentives on the intensive margin for both disability and retirement benefits. We also build on our previous work on the disincentives for long careers in the Social Security retirement program, where we calculate the implicit tax rate stemming from the tax and benefit structure of that program on the extensive margin (Goda, Shoven, and Slavov 2009). The implicit tax from working an additional year in the Social Security retirement program generally increases with age because benefit accrual declines after 35 years of work, after which additional years of earnings are unlikely to have a big effect on future retirement benefits.

The remainder of this paper proceeds as follows. Section II describes the relevant aspects of the SSDI program, including eligibility for benefits and the calculation of benefits. We also describe the data sources that we use to construct stylized earnings profiles, disability, and mortality hazards. Section III describes how we calculate the present discounted value of additional benefits earned from an additional dollar of earnings and from an additional year of 
work. Section IV presents results for average earners and high and low earners, and section V discusses policies that could change the incentives faced by workers. Section VI provides our conclusions.

\section{Background and Data}

\section{SSDI Financing and Benefit Calculations}

The SSDI program is financed by a payroll tax levied on employees and employers equal to 0.90 percent of earnings each, for a total of 1.8 percent of earnings. Economists generally believe that the incidence of both the employee and the employer portions of the payroll tax falls on workers; that is, after-tax earnings would be 1.8 percent higher without the SSDI program. All earnings below a taxable maximum, which is $\$ 118,500$ in 2015 and increases each year with the average wage index (AWI), are subject to the SSDI tax. Earnings above the taxable maximum are not subject to Social Security taxes and do not contribute to calculated benefits.

Disability benefits are paid by Social Security to people who "can’t work because they have a medical condition that's expected to last at least one year or result in death" (Social Security Administration 2015). The application process is lengthy and involves several steps to classify individuals as disabled and unable to work. In this paper, we do not focus on the criteria for determining disability, but rather on how earnings before disability onset affect eligibility for SSDI and the benefits received under the program. ${ }^{3}$

Qualifying for disability benefits requires individuals to meet an insured-status requirement that ensures they have worked long enough and recently enough. An individual

\footnotetext{
${ }^{3}$ Applicants are reviewed based on their capacity to work and the severity and type of their medical condition. This process generally takes three to five months. Readers interested in the application procedures and criteria for disability are referred to Social Security Administration (2014a).
} 
receives a Social Security credit for one quarter of work by earning a minimum amount of income. The minimum amount of income is $\$ 1,220$ in 2015 and increases each year with average wages. Up to four credits can be earned each year. Insured status is met by passing a "recent work" test and a "duration of work" test. The requirements for passing the recent work test and the duration of work test depend on the age at which a person becomes disabled and are summarized in tables 1 and 2 . While the qualification rules for eligibility before age 31 are somewhat different, an individual who becomes disabled at age 31 or older must have worked during five of the previous ten years in order to pass the recent work test. This rule essentially implies that someone who has worked for several years before exiting the labor market will continue to have eligibility for another five years. This requirement is the main driver of work incentives on the extensive margin, as each additional year worked extends eligibility by one year.

The work incentives on the intensive margin arise from how benefits are calculated if one is deemed to be disabled. The computation of disability benefits is somewhat similar to the computation of retirement benefits under Social Security, but differs in some important ways. SSDI benefits are calculated based on the worker's average indexed monthly earnings (AIME). The AIME is calculated in a series of steps. First, annual covered earnings are indexed either to the second calendar year before the year of disability or to the year in which the individual turns age 60 , whichever is earlier. The indexing is performed using the AWI, which reflects economywide average wage growth and is updated each year by the Social Security Administration (SSA). Our simulations assume that the AWI increases by 3.83 percent per year, in line with the intermediate assumption of the 2014 Social Security Trustees Report (SSA Trustees 2014) regarding the long-run growth rate of covered wages. Earnings in years after the indexing year 
are counted at their nominal value. Second, the number of computation years is determined. The number of years of earnings used to calculate the AIME is the number of full calendar years elapsed between age 21 and the year of disability, less the number of dropout years. One dropout year is allowed for every five years elapsed, up to a maximum of five dropout years. ${ }^{4}$ The number of computation years must be at least 2 and at most 35. Finally, the highest years' indexed earnings are summed and divided by the number of months in the computation period. For example, consider someone who began working upon turning age 18 and became disabled upon turning age 39 . The number of full calendar years between ages 21 and 39 is $17 .{ }^{5}$ One dropout year is allowed for each of the three full five-year periods in 17 years. Therefore, the person's 14 highest indexed years of earnings would be averaged to calculate the AIME.

The AIME is then translated to a monthly benefit amount, known as the primary insurance amount (PIA). This translation occurs through a nonlinear formula that provides a proportionally higher PIA for individuals with lower AIMEs. For workers who become disabled in 2015, the PIA equals the sum of 90 percent of the first $\$ 826$ of AIME, 32 percent of the next $\$ 4,154$ of AIME, and 15 percent of AIME over $\$ 4,980$. These dollar thresholds - or "bend points"- used to calculate PIA change each year with the AWI. The PIA calculation uses the bend points that are in place during the year of disability or the year in which the individual turns 62, whichever is sooner. Cost of living adjustments (COLAs) are applied to the PIA each year after it is calculated. Our simulations assume that future COLAs are 2.7 percent per year, in line with the long-run inflation assumption made in the intermediate scenario of the 2014 Trustees report (SSA Trustees 2014).

\footnotetext{
${ }^{4}$ The number of dropout years may be increased based on years spent on child care. However, because we focus on stylized workers, we ignore this provision.

${ }^{5}$ These are the 17 calendar years in which the individual turned ages 22 through 38 . The years in which the individual turned 21 and 39 are partial calendar years.
} 
Disabled beneficiaries are paid the PIA initially in the sixth month after disability occurs and until either recovery or attainment of normal retirement age, whichever comes first. ${ }^{6}$ Once a beneficiary attains normal retirement age, disability benefits are converted to retired worker benefits. However, the period of disability affects the calculation of retired worker benefits as years of disability are disregarded in the retirement PIA calculation. Thus, the level of benefits does not change at normal retirement age, and the presence of SSDI boosts retirement benefits relative to what could have been received by a nondisabled worker with an identical earnings history. Together, these features of the benefit calculation determine how SSDI affects work incentives on the intensive margin.

\section{Stylized Earnings}

We perform our analysis on stylized earnings histories to plainly illustrate the effect of program rules on work incentives. Our stylized-earnings histories are based on a methodology developed by the SSA Office of the Chief Actuary, which produces hypothetical earnings histories to illustrate a variety of different features of the Social Security program, including benefit levels, replacement rates, money's worth measures, and internal rates of return (Clingman and Burkhalter 2014). Please note that, while stylized earnings isolate the effect of program rules, they do not reflect years spent out of the labor force or fluctuations in earnings levels over one's career.

The Office of the Chief Actuary develops a set of scaled factors, on which their stylized earnings histories are based, through a series of steps. Using earnings from the Continuous Work

\footnotetext{
${ }^{6}$ Auxiliary disability benefits may also be payable to children and spouses of disabled workers, who are not taken into account in this analysis because of the focus on stylized earners. This omission would lead us to underestimate the returns to working for individuals with dependents, particularly those with young children who could receive auxiliary benefits for several years.
} 
History Sample, raw scaled factors are calculated by taking the ratio of average earnings at each age relative to the economy-wide AWI in each particular year. This type of calculation is superior to one that assumes workers earn a constant percentage of the AWI each year throughout their careers, as that method tends to ignore the life-cycle patterns of earnings that are typically low for younger and older ages and higher during prime working ages. An adjustment is applied to the raw factors for ages 62 and older to account for the fact that workers who tend to work beyond age 62 in the data may be selected from a nonrepresentative sample. The factors are also multiplied by the percentage of individuals at each age who are working to make them representative of all individuals, working or nonworking.

We generate stylized earnings histories by starting with these scaled factors and modifying them in a few different ways. First, we adjust the factors to be representative of someone who works in each year of life and therefore divide by the percentage of individuals with earnings at each age. Second, we are interested in simulating earnings for a wider set of ages (18-66) than is provided by the Social Security Administration (21-64), so we make some assumptions to extend the series. In particular, we assume that workers earn the same percentage of the AWI at ages $18-20$ as they earn at age 21 and that the same fraction of individuals work at ages $18-20$ as at age 21 . We assume that 65 - and 66 -year-olds earn the same nominal earnings as someone age 61 (an assumption similar to what SSA uses for earnings after age 61). We also assume that the same percentage of individuals works at ages 65 and 66 as at age 64 . While these assumptions are not completely plausible, our results are insensitive to reasonable changes in the stylized earnings levels for these years. Finally, we convert the earnings histories to the 1997 cohort (which turns 18 in 2015) using a projected AWI increase of 3.83 percent per year. 


\section{Disability and Mortality Hazards}

We use disability incidence rates and mortality hazards to determine the expected present value of changes in SSDI resulting from additional earnings or career length. Disability incidence rates are drawn from table 4 of Zayatz (2011), which reports awards per thousand by age, year of award, and gender for years between 1986 and 2009. We use the incidence rates for 2009 in our simulations. Because incidence rates are reported in five-year age intervals and create artificial discontinuities from one interval to the next, we smooth the incidence rates by assuming the values shown apply to the midpoint of each five-year interval and by linearly interpolating from one point to the next. The resulting incidence rates for 2009 , which we use in our simulations, are shown in figure 1. Disability incidence rates increase with age until age 62 but then decline. The decline after age 62 likely reflects the fact that many disabled individuals simply stop working and claim retirement benefits.

Mortality hazards for disabled individuals differ by age and by the length of time one is disabled. Zayatz (2011), in tables 8A-8C, reports survival tables for male and female disabled workers based on data during 2001-2005. We use these survival probabilities to discount any income received during years of disability to the year in which the individual became disabled. Survival probabilities for nondisabled individuals are based on the cohort mortality tables used in the intermediate scenario of the 2013 Social Security Trustees Report (SSA Trustees 2013). These survival probabilities are used to discount the expected value of any potential future disability awards. For example, consider the risk that a 24 -year-old faces of becoming disabled at age 31. In calculating the expected present value of the disability award that would be received in this scenario, the disabled survivor probabilities are used to discount income received after age 
31 to the year in which the individual is age 31 . The nondisabled survivor probabilities are used to further discount this amount to the year in which the individual is age 24 .

\section{Differences by Earnings}

We are interested in examining how work incentives vary for workers with different levels of earnings, which are also likely to be associated with different levels of disability incidence rates.

The Office of the Chief Actuary reports scaled factors that represent workers with careeraverage earnings levels equal to 25 percent, 45 percent, 100 percent, and 160 percent of the AWI. These factors simply shift the age-earnings profile up or down by a proportionate amount at each age. We refer to workers with career earnings equal to the AWI as "average" workers. Workers with career earnings equal to 25 percent, 45 percent, and 160 percent of the AWI are referred to as "very low," "low," and "high" earners, respectively. The stylized earnings profiles for each of the four earner types are shown in figure $2 .^{7}$

We combine these earnings profiles with information from von Wachter (2012) about disability incidence by education, reproduced in table 3. Von Wachter uses Current Population Survey data to report how incidence rates differ by education. We assume that the differences in incidence rates by education roughly correspond to differences in incidence rates by earnings levels as follows: the worker with career earnings equal to 25 percent of the AWI has disability incidence rates similar to those among individuals with less than a high school education, the worker with career earnings equal to 45 percent of the AWI has disability incidence rates similar to those among individuals with a high school education, the worker with career earnings equal to the AWI has disability incidence rates similar to those among individuals who have completed

\footnotetext{
${ }^{7}$ We adjust earnings levels slightly for the low-income earner so that a full year of work is enough to gain four Social Security credits.
} 
some college, and the worker with career earnings equal to 160 percent of the AWI has incidence rates similar to those among individuals with a college education or more. We use ratios from table 3 to generate incidence rates by earnings that imply the same proportional differences in incidence by education that are reported by von Wachter (2012), assuming that individuals with some college reflect the incidence rates for average earners. ${ }^{8}$ For instance, to generate incidence rates for very low earners, whom we assume to have disability hazards similar to those with less than a high school education, we multiply the incidence rates in figure 1 by $(0.79 / 0.37)$.

\section{Methodology}

\section{Calculating the Expected Value of SSDI}

We assume that each stylized earner was born on January $2,1997,{ }^{9}$ that decisions about labor force participation and earnings for each year are made at the beginning of the year, and that disability may occur on any subsequent birthday. Individuals in the 1997 birth cohort turn 18 in 2015 and have a normal retirement age of 67 . We assume that work begins at age 18 and ends upon either disability or reaching age 67 , whichever is sooner. We also assume that, once disabled, an individual remains disabled for the remainder of life; that is, we ignore the possibility of recovery. ${ }^{10}$

\footnotetext{
${ }^{8}$ The table presents three alternative sets of incidence rates based on different measures of SSDI receipt. We use the first measure reported, believed to be the most accurate. This measure counts individuals as receiving SSDI if they are receiving Social Security benefits for the reason of disability and are age 64 or younger.

${ }^{9}$ Our calculations are simplified if calendar years coincide with ages. Under Social Security rules, individuals born on the first of a month are treated as though they were born in the previous month. Thus, January 2 effectively corresponds to the start of the calendar year. See Social Security Administration (2008) for details.

${ }^{10}$ Allowing for the possibility of recovery significantly increases the dimensionality of the problem. Assuming that disability is permanent overstates the present discounted value of SSDI. In practice, the probability of recovery is less than 1 percent each year (Autor 2011). But if the probability of recovery varies with age, it may also bias our estimates of the pattern of work incentives over the life cycle. However, we note that our estimates of intensive margin work incentives are similar to those of Cushing (2005), who allows for the possibility of recovery.
} 
Mathematically, the expected present value of SSDI benefits in the event of disability starting at age $a$, and discounted to the year in which the individual turns $a$, is given by the following:

$$
B_{a}\left(E_{a-1}\right)=\sum_{t=a}^{T} \frac{s_{t}^{d, a} b_{t}\left(E_{a-1}\right)}{[(1+r)(1+\pi)]^{t-a}}-\sum_{t=\max (62, a)}^{T} \frac{s_{t}^{d, a} b_{t}^{R}\left(E_{a-1}\right)}{[(1+r)(1+\pi)]^{t-a}}
$$

Here $E_{a-1}=\left(e_{18}, e_{19}, \ldots, e_{a-1}\right)$ is the vector of earnings from age 18 through age $a-1 ; s_{t}^{d, a}$ is the probability of a disabled person surviving to age $t$ conditional on having survived to age $a$ (so, in the first term, $\left.s_{a}^{d, a}=1\right) ; r$ is the real interest rate; $\pi$ is the inflation rate; and $T$ is the maximum possible lifespan (assumed to be 110 years). In the first term, $b_{t}$ is the SSDI or converted retirement benefit received at age $t$; the SSDI benefit received in the first year is assumed to begin in June because of the five-month waiting period, and COLAs are applied to benefits in subsequent years. While payments made at or after normal retirement age are technically classified as retirement benefits, we include them because they are generally higher than the retirement benefits that would be available to a nondisabled individual with the same earnings history. The second term accounts for the fact that these post-age 66 benefits merely boost the value of benefits that would be available anyway. In this term, $b_{t}^{R}$ denotes the retirement benefit that could be received at age $t$ by a nondisabled individual with the same earnings history (i.e., with an earnings history in which work stops at the age of disability). The retirement benefit is assumed to be claimed at either age 62 or the age at which earnings stop, whichever is sooner. ${ }^{11}$ The appropriate actuarial reduction is applied for claims made before normal retirement age, and COLAs are applied to retirement benefits paid after age 62. In this formula, the real interest rate

\footnotetext{
${ }^{11}$ In general, individuals have to be age 62 throughout the entire first month in which they begin an early benefit. For most people, this means that benefits can begin only the month after they turn 62 . However, individuals who were born on the second day of the month, like our stylized workers, are treated as though they turned age 62 on the first day of the month and can thus receive benefits during the month in which they turn 62. See Olson (1999) for details.
} 
is set to 2.9 percent, in line with the long-run intermediate assumption made in the 2014 Trustees report (SSA Trustees 2014). The inflation rate is set to 2.7 percent, the same value used for the COLAs.

Now consider an individual currently age $i$ who faces a risk of disability onset at any future age $a=i+1, i+2, \ldots, 66$. The expected present discounted value of disability insurance for this individual is

$$
E V_{i}(E)=\sum_{a=i+1}^{66} \frac{I_{a} p_{a} s_{a}^{n, i} B_{a}\left(E_{a-1}\right)}{[(1+r)(1+\pi)]^{a-i}} .
$$

Here, $E=\left(e_{18}, e_{19}, \ldots, e_{66}\right)$ is the full earnings history from age 18 to age 66 assuming that no disability occurs, $I_{a}$ is an indicator equal to 1 if the individual is eligible for SSDI at age $a$ and 0 otherwise, $s_{a}^{n, i}$ is the probability that a nondisabled person survives to age $a$ conditional on survival to age $i$, and $p_{a}$ is the probability of becoming disabled at age $a$. In other words, the overall expected value of SSDI is the discounted sum of the expected value of SSDI across all possible future ages of disability onset.

For example, consider a male average earner (i.e., someone with career-average earnings equal to the AWI) who begins work at age 18. Suppose this individual becomes disabled at age 33 (in January 2030). The number of computation years is nine (the number of full calendar years between ages 21 and 33, minus two dropout years). Earnings are indexed to their 2028 levels, with 2029 earnings counted at their nominal value. The top nine years of indexed earnings are averaged to produce an AIME of $\$ 5,976.42$, resulting in a PIA of $\$ 2,754.34 .{ }^{12}$ This PIA calculation assumes that the 2015 bend points of $\$ 826$ and $\$ 4,980$ are increased by 3.83 percent per year, reflecting growth in the AWI. The individual receives his or her PIA during each of the last seven months of 2030 (reflecting the five-month delay period). In subsequent years, the

\footnotetext{
${ }^{12}$ For simplicity, we ignore the SSA's practice of rounding PIAs down to the nearest 10 cents.
} 
individual receives the PIA each month, with the addition of a 2.7 percent COLA for each year after 2030. A nondisabled individual with the same earnings history (i.e., with zero earnings from age 33 onward) would be entitled to a monthly retirement benefit of $\$ 3,086.47$ starting at age 62, with COLAs added in subsequent years. ${ }^{13}$ SSDI provides postretirement income only to the extent that it boosts that amount. ${ }^{14}$ Discounting the stream of income from SSDI, net of what would be available anyway from the retirement program, produces a sum of $\$ 548,174.06$. This value is $B_{33}\left(E_{32}\right)$ from equation (1), the expected present value of SSDI if disability occurs at age 33. A similar calculation can be performed for every potential age of disability onset from 19 through 66. From the perspective of any age $i$, taking the expectation of $B_{a}\left(E_{a-1}\right)$ across all future ages $(a>i)$ produces $E V_{i}(E)$ from equation (2).

\section{Intensive Margin}

To calculate the intensive margin work effect, we assume that individuals work a full career, with the earnings profiles given in figure 2 , and we examine the effect of increasing earnings by $\$ 1$ at each age on the expected present value of SSDI benefits at that age. That is, for each age $i$, we calculate



For example, consider a male average earner (with career-average earnings equal to the AWI) who began work at 18 , has just turned 24 , and is considering earning an extra dollar during the coming year. This additional dollar changes the present value of SSDI benefits in subsequent

\footnotetext{
${ }^{13}$ The AIME, calculated using 35 computation years and indexing earnings to age 60 , is $\$ 5,954.28$. Applying the bend points in place at age 62 (again, assuming that these grow at 3.83 percent per year) results in a PIA of $\$ 4,409.25$. An individual who claims at age 62 receives 70 percent of the PIA, or $\$ 3,086.47$.

${ }^{14}$ Because there is no waiting period for retirement benefits, SSDI lowers income during the first year of disability if disability occurs at age 62 or later, but SSDI raises income in all subsequent years.
} 
years. For example, the value of future SSDI benefits conditional on disability onset at age 25 goes up by $\$ 2.17$; this is the increase in $B_{25}\left(E_{24}\right)$ from equation (1). In fact, the expected value of SSDI— $B_{a}\left(E_{a-1}\right)$ from equation (1)—increases at all ages of disability onset until age 37 . For disability onset at age 37 or later, earnings at age 24 get dropped and no longer increase SSDI payments - the first term in equation (1). However, age 24 earnings do increase the retirement benefits that would be available anyway - the second term in equation (1) - until age 59 , as retirement benefits for nondisabled individuals are calculated based on the highest 35 years of earnings. Thus, an additional dollar of earnings reduces the net value of SSDI for onset between 37 and 59 and has no effect on the net value of SSDI for onset after age 59. Discounting and summing these changes in $B_{a}\left(E_{a-1}\right)$ over all future possible dates of disability onset produces an increase of 1.97 cents ( 1.97 percent of the additional dollar earned) in the overall present discounted value of SSDI benefits. To examine the intensive margin work effort, we compare this value with the 1.8 percent SSDI payroll tax that would be paid on the extra dollar earned.

\section{Extensive Margin}

To calculate the extensive margin work incentive at each age $i$, we assume that individuals have worked until age $i-1$ and received earnings according to the profiles in figure 2 . Then, we examine the effect of working for an additional year compared with stopping work forever. That is, we calculate

$$
\text { Extensive } \operatorname{margin}_{i}=\frac{E V_{i}\left(e_{18}, \ldots, e_{i}, 0, \ldots, 0\right)-E V_{i}\left(e_{18}, \ldots, e_{i-1}, 0, \ldots, 0\right)}{e_{i}} .
$$

We consider two alternative assumptions about $e_{i}$, the earnings in the additional year of work. First, we assume that the individual earns the minimum amount required to earn four quarters worth of Social Security credits for the year. This minimum amount is $\$ 4,880$ (i.e., $\$ 1,220 \times 4$ ) 
in 2015 , and we assume it increases by 3.83 percent, in line with expected increases in the AWI, in each subsequent year. In other words, the individual earns just enough to extend eligibility under the recent work test. This calculation captures the effect of working at the minimum income versus not working, and we refer to it as the minimum earnings extensive margin. Second, we assume the individual earns the amount specified in the stylized earnings profile. This calculation captures the effect of working a full year versus not working, and we refer to it as the full earnings extensive margin. ${ }^{15}$

For example, consider a male average earner who has just turned 24 in January 2021 and has worked since age 18 . This individual clearly meets the duration of work test shown in table 2. Under the recent work test shown in table 1, if this individual stops work now, eligibility for SSDI would continue for another two years. Specifically, the second row of table 1 applies for disability onset at ages 25-30. The individual would have worked for 11 quarters since turning 21 - that is, starting with the second quarter of 2018 and ending with the fourth quarter of 2020. For disability onset at age 25 , there are 16 quarters between the quarter after turning 21 and the quarter of disability. Since $11 / 16>0.5$, the individual is eligible. For disability onset at age 26, there are 20 quarters between the quarter after turning 21 and the quarter of disability. Because $11 / 20>0.5$, the individual is eligible. However, for disability onset at age 27 or later, there are at least 24 quarters between the quarter after turning 21 and the quarter of disability, and 11/24< 0.5. Thus, the individual loses eligibility. Now suppose the individual continues working until age 25, in January 2022. The additional year of work extends the number of quarters worked to 15. Because $15 / 24>0.5$, the individual would continue to be eligible for SSDI if disability

\footnotetext{
${ }^{15}$ The stylized earnings profiles are actually based on average earnings for all workers, including those who work part time. In the extensive margin calculations, we refer to these earnings as "full earnings" for convenience in distinguishing them from the minimum earnings required to extend SSDI eligibility.
} 
occurs at age 27 . He or she would also continue to be eligible at age 28 , as $15 / 28>0.5$. However, eligibility would be lost at age 29 (as $15 / 32<0.5$ ) in the absence of additional work. If earnings during the additional year of work are equal to the minimum required to receive credits during this year, there is no increase in the value of benefits conditional on disability at ages 25 and 26 - in other words, $B_{25}\left(E_{24}\right)$ and $B_{26}\left(E_{25}\right)$ from equation (1). There is no increase because the minimum income year does not enter the benefit computation and therefore does not increase benefits. However, the expected values of SSDI conditional on disability onset at ages 27 and 28-the two additional years of eligibility that are earned by working at age $24-$ are $\$ 327,863.17$ and $\$ 324,898.60$, respectively. These represent $B_{27}\left(E_{26}\right)$ and $B_{28}\left(E_{27}\right)$ from equation (1). Discounting these amounts to age 24 and accounting for the probability of disability at 27 and 28 yields $\$ 615.55$ and $\$ 600.37$, respectively. Thus, the increase in the value of SSDI from working at minimum income is $\$ 615.55+\$ 600.37=$ $\$ 1,215.92$. The minimum income required to earn four credits in 2021 is $\$ 4,880 \times 1.0383^{6}=$ $\$ 6,114.44$. Thus, the increase in the value of SSDI is 19.9 percent $(\$ 1,215.92 / \$ 6,114.44)$ of earnings during the year. Comparing this with the 1.8 percent tax paid on these earnings illustrates the minimum earnings extensive margin.

If the additional year of work represents a full year of earnings - that is, at the earnings specified in the earnings profile from figure 2- then the additional year of work boosts SSDI benefits conditional on disability at ages 25 and 26 by $\$ 26,890.46$ and $\$ 27,494.74$, respectively, for average earners. These represent the increases in $B_{25}\left(E_{24}\right)$ and $B_{26}\left(E_{25}\right)$ that result from working at age 24 . Discounting these amounts to age 24 and taking into account the probability of disability at these ages yields $\$ 75.57$ and $\$ 51.31$, respectively. The additional year of work also extends eligibility by two years. The expected values of SSDI conditional on disability at 
ages 26 and 27 are $\$ 359,694.44$ and $\$ 356,427.85$, respectively. These are $B_{27}\left(E_{26}\right)$ and $B_{28}\left(E_{27}\right)$ from equation (1). These amounts are higher than in the minimum earnings scenario because the higher level of earnings at age 24 increases the expected disability benefit available at ages 27 and 28. Discounting these amounts to age 24 and taking into account the probability of disability at 27 and 28 yields $\$ 666.50$ and $\$ 640.72$, respectively. Summing the increases in the expected value of SSDI yields $\$ 666.50+\$ 640.72+\$ 75.57+\$ 51.31=\$ 1,434.11$, the increase in the overall expected present value of SSDI at age 24. This amount represents 3.6 percent of earnings at age 24 (which are $\$ 39,800.01$ according to the average earnings profile in figure 2), and comparing this amount with the 1.8 percent SSDI payroll tax illustrates the full earnings extensive margin work incentive.

\section{Results}

\section{Intensive Margin}

Figure 3 shows the increase in the value of SSDI benefits from earning an additional dollar for men and women with average earnings. Comparing these increases with the 1.8 percent SSDI tax rate (the solid horizontal line) reveals the intensive margin work incentive. For both men and women, the benefit from earning an extra dollar is relatively low early in life. This level is low because these low-earning years stop affecting SSDI benefits once they are replaced by higherearning years in the AIME calculation. Indexed earnings are lowest at age 21; therefore this year of earnings is the first to be dropped, resulting in a very small increase in SSDI benefits. The benefit from earning an extra dollar peaks at age 27, after which it declines gradually, reaching (almost) zero at age 63. This pattern arises because (a) the increase in SSDI benefits applies to disability that occurs in any future year before normal retirement age and (b) SSDI benefits after 
the normal retirement age are limited. As normal retirement age approaches, there are fewer future years in which disability could occur. In addition, benefits received at younger ages are paid over a longer period. Starting at age 66 , there are no future years in which disability could occur, and therefore the benefit from earning an additional dollar at this age is exactly zero.

The increase in the value of SSDI from earning an additional dollar exceeds the 1.8 percent tax paid until age 38 for men and age 41 for women. At this point, the return from earning an additional dollar relative to the tax paid becomes negative. Once workers reach their early 60 s, they face a net tax rate that is very close to the full 1.8 percent payroll tax rate. While the patterns for men and women are similar, there are some gender differences that arise from differences in disability incidence and mortality. In particular, as shown in figure 1, disability incidence rates tend to be similar for men and women until the mid 50s, at which point the incidence rate rises for men relative to women. Also, both healthy and disabled women tend to have lower mortality.

These results are similar to the intensive margin calculations that Cushing (2005) reports. Cushing's results suggest that workers initially receive a positive net return on their SSDI taxes. However, this return declines steadily, becoming negative around age 35 . Workers in their early sixties face net tax rates that are close to the full 1.8 percent.

\section{Extensive Margin}

Figures 4 and 5 show the minimum earnings and full earnings extensive margin effects, respectively, for men and women by comparing the increase in the expected value of SSDI from working an additional year with the 1.8 percent SSDI payroll tax rate. From ages 18 through 26, the additional benefit from an additional year's work fluctuates because of the special rules for 
the recent work test for individuals under age 31 (see table 1). In these years, an additional year of work may extend eligibility by either one or two years. While these fluctuations appear large, it is important not to overinterpret them. Most 18-26-year-olds do not make decisions about whether to quit work permanently or continue for an additional year. Thus, the work incentives reflected in these extensive margin calculations are not meaningful for these workers. The decision to retire permanently is mainly relevant for older workers, so the extensive margin calculations should be interpreted with caution outside of this group. ${ }^{16}$

Beyond age 26, each additional year of work extends eligibility by exactly one year. The value of that additional year of eligibility varies as a result of two factors. First, the hazard of disability generally increases with age (at least until the early 60s), a factor that tends to increase the value of the additional year of eligibility. Second, the benefits awarded later in life are paid over a shorter period, a factor that tends to reduce the value of any benefits commenced during the extra year of eligibility. These two factors push in opposite directions, resulting in a humpshaped pattern of the expected value of SSDI from working an additional year. That is, for both men and women, the benefit from an additional year of work generally increases until age 50 and then starts to decline.

On the minimum earnings extensive margin (figure 4), the benefit from an additional year of work is substantial for both men and women. At age 50, the return from working an additional year, net of the 1.8 percent payroll tax, is more than 35 percent. The value of an additional year of work drops below the 1.8 percent SSDI tax rate at age 61 for both men and women. It becomes zero at age 62 and later as the additional year of work at such a low level of income

\footnotetext{
${ }^{16}$ We perform a similar calculation for the incentive to take one year off from working, a decision that may be more relevant to younger workers. We find that the reduction in benefits from one year of nonparticipation is relatively small because eligibility is unaffected and because a provision for dropout years is in the benefit calculation.
} 
neither extends eligibility nor increases benefits in the event of disability. On the full earnings extensive margin (figure 5), the benefit from an additional year of work is much more modest, reaching less than 1.5 percent of earnings (net of the 1.8 percent payroll tax) at age 50 . The value of an additional year of work drops below 1.8 percent at age 57. It reaches close to (but not exactly) zero at age 62 , as additional years of work at full earnings do not extend eligibility but do modestly increase benefits in the event of disability.

Overall, extensive margin work incentives remain positive much longer than intensive margin work incentives. However, in the early $60 \mathrm{~s}$, both intensive and extensive margin work incentives are negative, and workers face close to the full 1.8 percent SSDI tax. The extensive margin benefit is close to zero starting at age 62 , as additional years of work do not extend eligibility at all. All 62-year-olds who have worked for the past five years have already met the recent work test through age 67 , at which point they receive only retirement benefits that would have been available anyway. If earnings are high enough, additional years of work at age 62 or later can boost AIME and, therefore, the benefit that would be paid upon disability. However, this effect is very small. Thus, the structure of SSDI provides a strong incentive for older workers to continue working part time at least through age 60 , but the structure provides a disincentive to earn a full level of earnings beyond age 55 or to earn additional income after around age 40 . There is also a disincentive to participate in the labor force and to earn additional income beyond age 60 .

\section{Differences by Earnings}

Figures 6,7 , and 8 show the intensive margin, minimum earnings extensive margin, and full earnings extensive margin effects, respectively, for male workers with different levels of 
earnings. While the pattern of work incentives over the life cycle is similar, figures 6 and 8 show that SSDI clearly transfers income from high to low earners. This transfer results from the progressivity of the benefit formula and from the fact that the risk of disability is assumed to decline with earnings. High earners face work disincentives (i.e., benefit accrual rates that are less than 1.8 percent) on both the intensive and full earnings extensive margins throughout their careers. Workers with very low earnings face positive work incentives on the intensive margin until age 50 and on the full earnings extensive margin until age 59. Figure 7 shows that workers at all levels of earnings face positive work incentives on the minimum earnings extensive margin throughout most of their careers. Thus, older workers at any earnings level face positive incentives to earn a minimum level of earnings through age 61 , but they often face disincentives for earning additional income, particularly at higher earnings levels. The pattern of redistribution is less obvious from figure 7 as the additional year of work for all levels of earnings is assumed to produce the same (minimum) level of earnings. The absolute level of benefits is greater for individuals with higher earnings but their probability of disability is lower, so there is no clear pattern in the increase in the expected value of SSDI relative to the additional income earned.

\section{Policy Implications}

The patterns in the intensive and extensive margin work incentives from the SSDI program mainly stem from two features of the program. First, to be eligible to receive benefits, individuals must pass a recent work test, implying that exiting the labor force affects benefit eligibility at some point in the future. Second, disability benefits are converted to retirement benefits at the normal retirement age and terminated at death, leading to a declining period over which benefits are paid as workers advance in age. The combination of these two features leads 
to almost no increase in the present value of SSDI benefits as a result of working beyond age 61. Once an individual has worked to age 61, eligibility for SSDI is already guaranteed through age 66. At this point, extending eligibility has no value, as the additional years of eligibility occur after normal retirement age. Moreover, any substantial increase in benefits as a result of the extra work is paid over an extremely short period. This result is true regardless of the level of earnings assumed or gender, and it suggests that the 1.8 percent SSDI payroll tax is almost a pure tax on earnings, which could discourage work at older ages.

We are not aware of any empirical evidence on the effect of these incentives on labor supply. The disability benefit formula is complicated, and it is possible that individuals do not calculate or understand the labor supply incentives it creates. However, other studies have examined the perceived labor supply incentives (Liebman and Luttmer 2014) and effect on labor supply (Liebman, Luttmer, and Seif 2009) of the Social Security retirement program, which has similarly complex rules. Liebman and Luttmer (2014) find that people are generally aware of the link between Social Security benefits and earnings, although they are less familiar with the rules governing the earnings test, the spousal benefit, and the number of years that enter into the benefit calculation. Liebman, Luttmer, and Seif (2009) find that, on the extensive margin, a 10 percent increase in the net-of-tax share (which is defined as 1 minus the effective tax rate and represents the fraction of income that is retained by the worker) reduces the probability that a worker will retire in the next two years by around 14 percent. On the intensive margin, they find that hours worked, but not earnings, respond to changes in benefit accrual. Whether the incentives in the SSDI program are perceived similarly or have a similar effect on behavior remain questions for further research. 
To provide a starting point for thinking about the incentive effect of modifications to the benefit formula, we discuss one policy that might reduce work disincentives for older workers: exempt earnings from the SSDI payroll tax beyond age 60. Under this policy, workers would remain eligible for SSDI benefits if they were eligible at age 60, and earnings earned beyond this age would not affect their benefit calculation. The payroll tax at younger ages could be increased slightly to keep the system revenue-neutral in the aggregate. Depending on the incidence of the payroll tax, this policy could affect either labor supply among older workers by increasing the take-home pay of those affected or labor demand by encouraging more firms to hire older workers. While the SSDI payroll tax is small relative to that dedicated to retirement benefits or Medicare, the SSDI payroll tax rate is imposed on top of other payroll taxes, and older workers have relatively high labor supply elasticities (French 2005). Thus, exempting workers age 61 and older from SSDI payroll taxes could have an important effect.

Our results also show stark differences in the value of extending eligibility for SSDI benefits versus the value of marginal increases in these benefits from additional earnings. Generally speaking, the main benefit from the SSDI program of continued work is to insure against the risk of becoming disabled in the future rather than to transfer resources from working years into retirement (as the Social Security retirement program does). Because the hazard of becoming disabled increases with age faster than the minimum required earnings for an additional year of SSDI eligibility, the benefit of continuing in the labor force increases until age 50. After this point, the reduction in the period over which benefits are paid reduces the return from the SSDI program of participating in the labor force. The program could be made more age neutral by adjusting the minimum required earnings amount by age. However, it is not clear from 
our results that the existing pattern creates distortions that concentrate earnings at ages at which the work incentives from the minimum earnings extensive margin are high.

\section{Conclusions}

This paper summarizes the returns to working on the intensive and extensive margins from the SSDI program. We use stylized earnings histories, disability incidence, and mortality rates from recent Social Security experience, and details of the eligibility and benefit computation rules to show how the expected increase in disability benefits received from earning an additional dollar or working an additional year vary over the life cycle. Our findings suggest that the returns to earning an additional dollar of income at a full level of earnings decline during the prime working years, starting above the combined SSDI payroll tax rate of 1.8 percent of earnings and declining to almost zero as one approaches the normal retirement age. These findings, consistent with previous research, suggest that the SSDI program creates incentives for workers to earn more income earlier in the life cycle when they have a greater chance of influencing the level of SSDI benefits that they would receive, and over a longer time horizon, compared to later in life.

Our findings on the extensive margin show a different picture. The returns to extending one's career depend on the level of earnings one is expected to receive. If an individual is considering participating in the labor force just enough to extend his or her eligibility, the return to working is substantial and as high as 35 percent of earnings at age 50. However, because in later years the return to earning amounts above the minimum required for eligibility are much lower, an additional full year of earnings provides a much more modest return relative to the disability payroll tax paid. The returns are positive for our male and female stylized workers between the ages of 35 and 56, peaking at age 50 and dropping below the SSDI payroll tax rate 
after that. The benefit from working an additional year approaches zero at age 62 , implying that the payroll tax is almost a pure tax after this point. The nonmonotonic nature of the relationship between age and the benefit from working an extra year comes from two opposing forces: on the one hand, disability incidence rates increase with age and working an additional year is valuable because it extends the period of eligibility for disability benefits; on the other hand, the period over which SSDI substantially boosts income decreases as one approaches normal retirement age and the end of life.

The implication of these findings is that the returns to participating in the labor force and earning the minimum required to extend eligibility for SSDI benefits, net of the payroll tax, is positive for workers during many of their prime working years and well into their 50s. However, the returns become negative after age 60 for average earners and therefore provide a disincentive to remain in the labor force. Earning more than the minimum required provides much smaller returns, only affecting disability benefits paid if earnings in the year in question increase the calculated disability benefit. Starting at age 57, workers face disincentives for earning a full year of earnings. These extensive margin net tax rates are most relevant to the decision to exit the labor force permanently and therefore do not have much significance at younger ages.

Our results highlight the importance of accounting for different levels of past earnings and examining margins that are relevant for workers. In particular, work incentives in the SSDI program on the intensive and extensive margins depend on the career-average level of earnings in a similar way, as future SSDI benefits depend on average earnings. An added complexity is that SSDI benefits also depend on one's earnings history, leading to potentially different conclusions depending on the earnings history that is assumed. In particular, our analysis is 
based on stylized workers and therefore may not represent the different earnings patterns and career interruptions that actual workers experience.

While examining actual workers' earnings histories remains an important direction for future work, we explore how work incentives vary by earnings levels and find similar patterns over the life cycle, although at different levels because of redistribution in the SSDI program. In addition to the fact that disability benefits are higher as a percentage of predisability earnings for low earners, we also assume that stylized workers with lower levels of earnings experience higher rates of disability incidence. As a result, the returns to working are much higher for those with lower levels of earnings than for those with higher levels of earnings.

The SSDI payroll tax rate of 1.8 percent of earnings is low relative to that dedicated to retirement benefits, and we are not aware of any empirical evidence on how much the work incentives in the benefit formula actually change behavior. However, the SSDI payroll tax is layered on top of payroll taxes levied for the retirement program and income taxes, and other research shows that older workers are particularly responsive to work incentives. One policy option that could reduce work disincentives at older ages is a "paid up" rule, under which workers over a certain age are exempt from SSDI payroll taxes. 


\section{References}

Autor, David H. 2011. "The Unsustainable Rise of the Disability Roles in the United States: Causes, Consequences, and Policy Options." National Bureau of Economic Research (NBER) Working Paper 17697, NBER, Cambridge, MA.

Autor, David H., and Mark G. Duggan. 2003. “The Rise in the Disability Rolls and the Decline in Unemployment." Quarterly Journal of Economics 118 (1): 157-206.

Clingman, Michael, and Kyle Burkhalter. 2014. "Scaled Factors for Hypothetical Earnings Examples under the 2014 Trustees Report Assumptions.” Actuarial Note 2014.3, Social Security Administration, Washington, DC.

Cushing, Matthew J. 2005. "Net Marginal Social Security Tax Rates Over the Life Cycle." National Tax Journal 58 (2): 227-45.

French, Eric. 2005. "The Effects of Health, Wealth, and Wages on Labour Supply and Retirement Behaviour." Review of Economic Studies 72 (2): 395-427.

Goda, Gopi Shah, John Shoven, and Sita Nataraj Slavov. 2009. "Removing the Disincentives in Social Security for Long Careers." In Social Security Policy in a Changing Environment, edited by Jeffrey Brown, Jeffrey Liebman, and David Wise, 21-23. Chicago: University of Chicago Press.

Liebman, Jeffrey B., and Erzo F. P. Luttmer. 2014. "The Perception of Social Security Incentives for Labor Supply and Retirement: The Median Voter Knows More Than You'd Think." National Bureau of Economic Research (NBER) Working Paper 20562, NBER, Cambridge, MA.

Liebman, Jeffrey B., Erzo F. P. Luttmer, and David G. Seif. 2009. “Labor Supply Responses to Marginal Social Security Benefits: Evidence from Discontinuities.” Journal of Public Economics 93 (11-12): 1208-23.

Maestas, Nicole, Kathleen J. Mullen, and Alexander Strand. 2013. "Does Disability Insurance Receipt Discourage Work? Using Examiner Assignment to Estimate Causal Effects of SSDI Receipt.” American Economic Review 103 (5): 1797-1829.

Olson, Janice A. 1999. “Who Is ‘62 Enough'? Identifying Respondents Eligible for Social Security Early Retirement Benefits in the Health and Retirement Study." Social Security Bulletin 62 (3): 51-56.

Social Security Administration. 2008. Social Security Benefits: Benefit Reduction for Early Retirement. Washington, DC: Social Security Administration. http://www.ssa.gov/oact/quickcalc/earlyretire.html.

.2014a. Annual Statistical Report on the Social Security Disability Insurance Program, 2013. Washington, DC: Social Security Administration. http://www.ssa.gov/policy/docs/statcomps/di_asr/. 
—.2014b. Annual Statistical Supplement to the Social Security Bulletin, 2014. Washington, DC: Social Security Administration.

http://www.ssa.gov/policy/docs/statcomps/supplement/2014/supplement14.pdf.

- 2015. Disability Benefits. Washington, DC: Social Security Administration. http://www.ssa.gov/pubs/EN-05-10029.pdf.

Social Security Administration (SSA) Board of Trustees. 2013. Annual Report of the Board of Trustees of the Federal Old-Age and Survivors Insurance and Federal Disability Insurance Trust Funds. Washington, DC: Social Security Administration.

- 2014. Annual Report of the Board of Trustees of the Federal Old-Age and Survivors Insurance and Federal Disability Insurance Trust Funds. Washington, DC: Social Security Administration.

von Wachter, Till. 2012. "Assessing Systematic Differences in Industry-Award Rates of Social Security Disability Insurance.” National Bureau of Economic Research (NBER) Retirement Research Center Working Paper NB12-13, NBER, Cambridge, MA.

Zayatz, Tim. 2011. "Social Security Disability Insurance Program Worker Experience." Actuarial Study 122, Social Security Administration, Washington, DC. 


\section{Table 1. Recent Work Test}

\begin{tabular}{lr}
\hline If you become disabled ... & Then you generally need ... \\
\hline $\begin{array}{l}\text {.. in or before the quarter } \\
\text { you turn age } 24 .\end{array}$ & $\begin{array}{r}\text {. } 1.5 \text { years of work during the 3-year } \\
\text { period ending with the quarter your } \\
\text { disability began. }\end{array}$
\end{tabular}

... in the quarter after you turn age 24 but before the quarter you turn age 31 .

... in the quarter you turn age 31 or later.
... to work during half the time for the period beginning with the quarter after you turned age 21 and ending with the quarter you became disabled.

Source: Social Security Administration, Disability Benefits (Washington, DC: Social Security Administration, 2015), http://www.ssa.gov/pubs/EN-0510029.pdf.

\section{Table 2. Duration of Work Test}

\begin{tabular}{lc}
\hline Age of disability & Number of years of work needed \\
\hline Before 28 & 1.5 \\
30 & 2 \\
34 & 3 \\
38 & 4 \\
42 & 5 \\
44 & 5.5 \\
46 & 6 \\
48 & 6.5 \\
50 & 7 \\
52 & 7.5 \\
54 & 8 \\
56 & 8.5 \\
58 & 9 \\
60 & 9.5 \\
\hline
\end{tabular}

Source: Social Security Administration, Disability Benefits (Washington, DC: Social Security Administration, 2015), http://www.ssa.gov/pubs/EN-0510029.pdf.

Note: The table does not cover all situations. 
Figure 1. Disability Incidence Rates, 2009

25



Source: Tim Zayatz, "Social Security Disability Insurance Program Worker Experience" (Actuarial Study 122, Social Security Administration, Washington, DC, 2011), table 4.

Note: Rates are linearly interpolated within five-year age intervals. 


\section{Figure 2. Stylized Earnings Profiles}

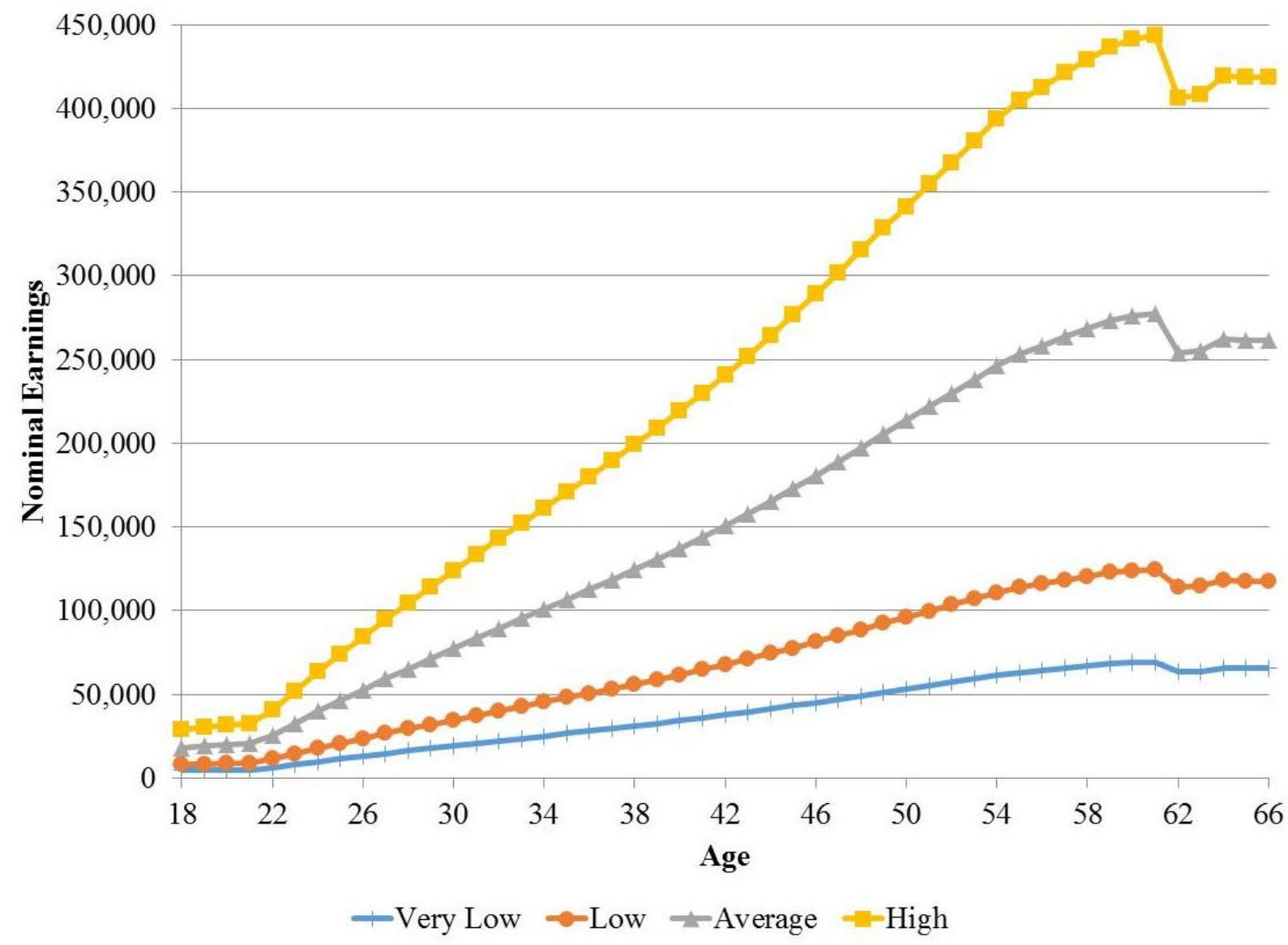

Source: Authors' calculations based on Michael Clingman and Kyle Burkhalter, "Scaled Factors for Hypothetical Earnings Examples under the 2014 Trustees Report Assumptions" (Actuarial Note 2014.3, Social Security Administration, Washington, DC, 2014), for cohort born in 1997. See text for details.

\section{Table 3. Disability Incidence Rates by Educational Attainment}

\begin{tabular}{lc}
\hline Education category & SSDI incidence, \% \\
\hline Less than high school & 0.79 \\
Equal high school & 0.57 \\
Some college & 0.37 \\
College or beyond & 0.17 \\
\hline
\end{tabular}

Source: Reproduced from Till von Wachter, “Assessing Systematic Differences in Industry-Award Rates of Social Security Disability Insurance" (National Bureau of Economic Research Retirement Research Center Working Paper NB12-13, NBER, Cambridge, MA, 2012), using first definition of SSDI receipt, which counts a person as receiving SSDI if the reason for receiving Social Security benefits is disability and the person is under age 64 . 
Figure 3. Intensive Margin Work Incentives by Gender (Average Earners)



- -Benefit from earning extra dollar - males $\rightarrow$ Benefit from earning extra dollar - females

Source: Authors' calculations based on equation (3). See text for more details. 
Figure 4. Minimum Earnings Extensive Margin Work Incentives by Gender (Average Earners)

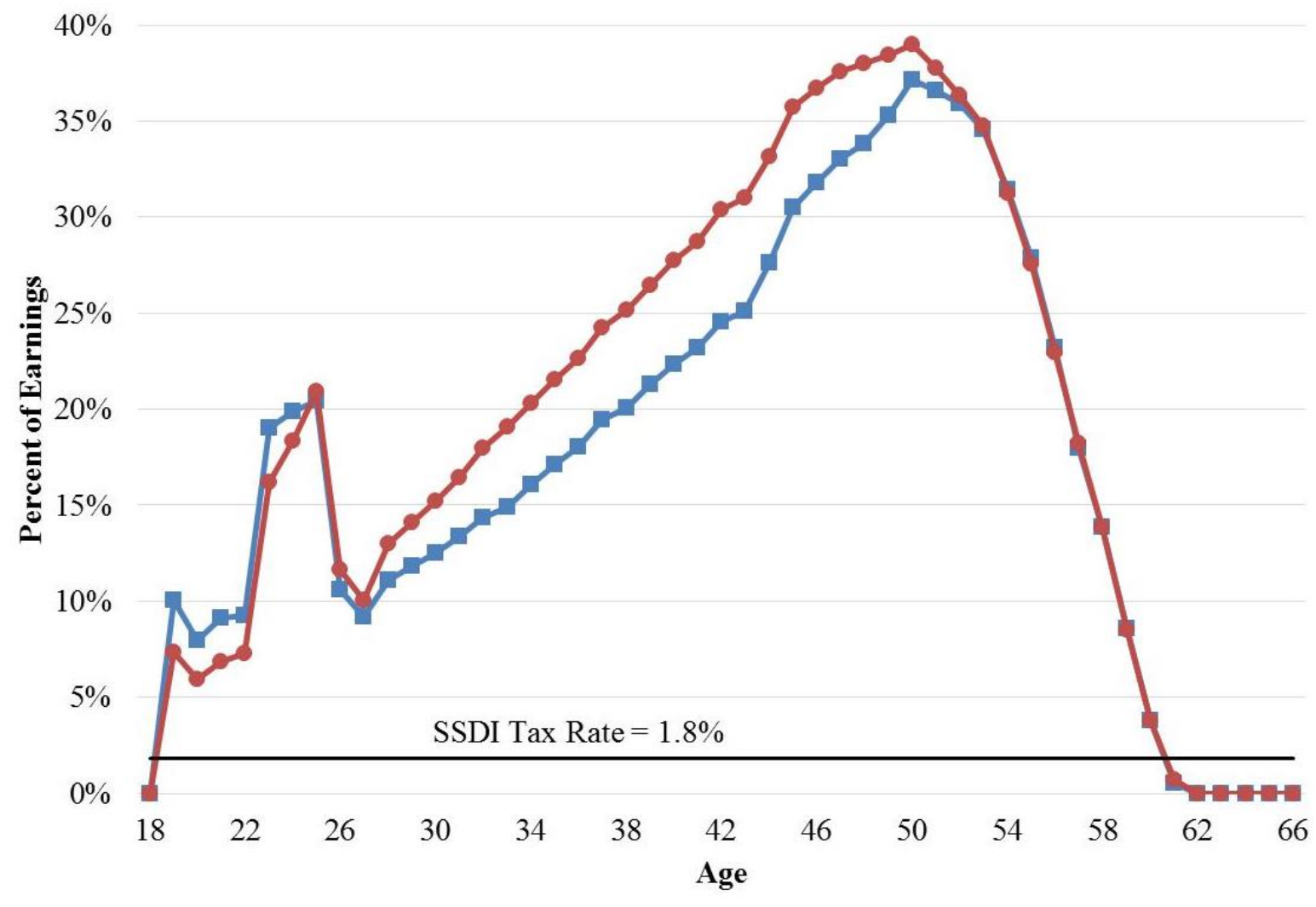

$\rightarrow-$ Benefit from working extra year - males $\rightarrow$-Benefit from working extra year - females

Source: Authors' calculations based on equation (4). Workers are assumed to earn the minimum amount required to earn Social Security credits during the additional year of work. See text for more details. 
Figure 5. Full Earnings Extensive Margin Work Incentives by Gender (Average Earners)

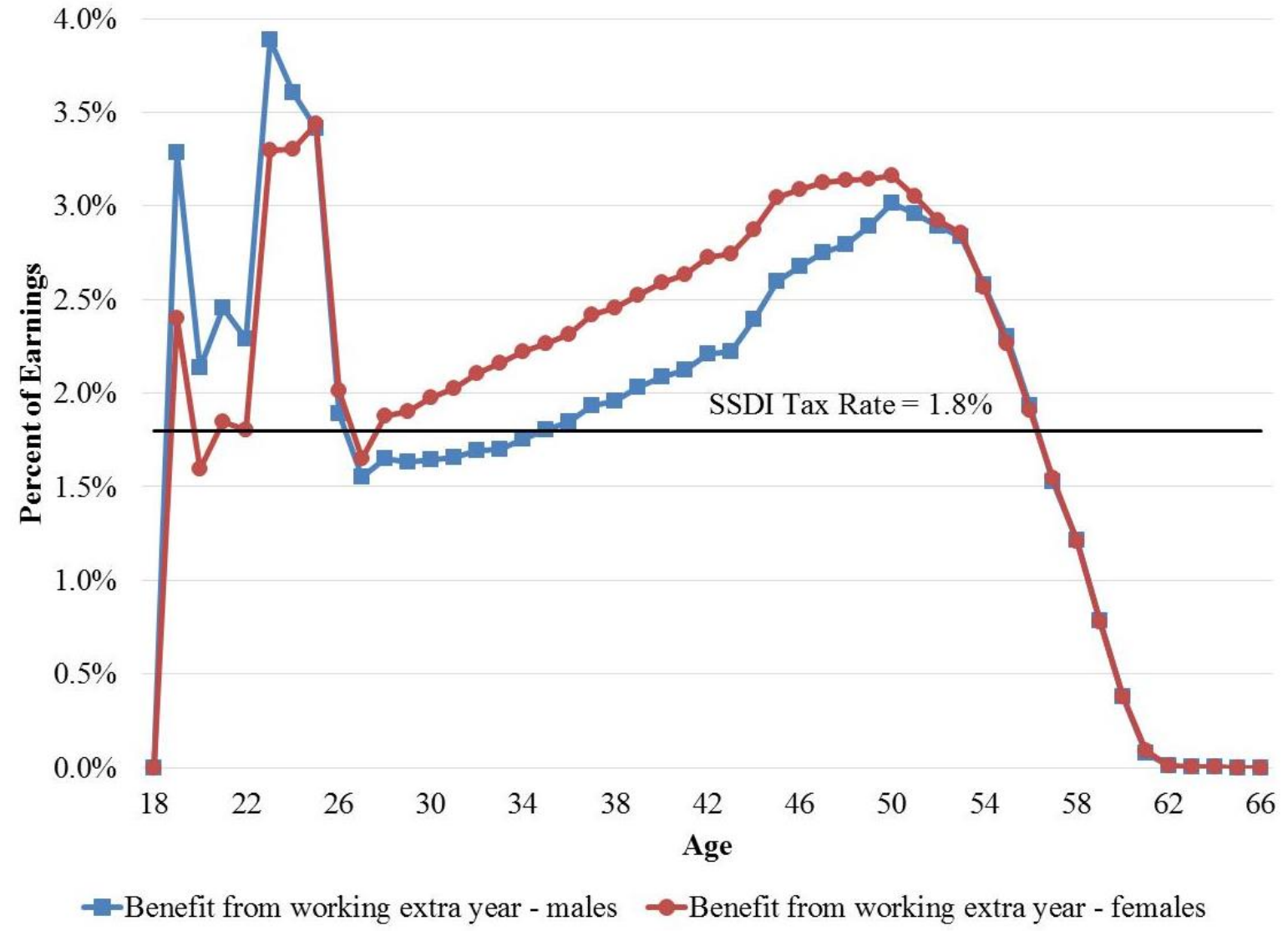

Source: Authors' calculations based on equation (4). Workers are assumed to earn the amount shown in the average earnings profile in figure 2 during the additional year of work. See text for more details. 
Figure 6. Intensive Margin Work Incentives by Earnings (Males)

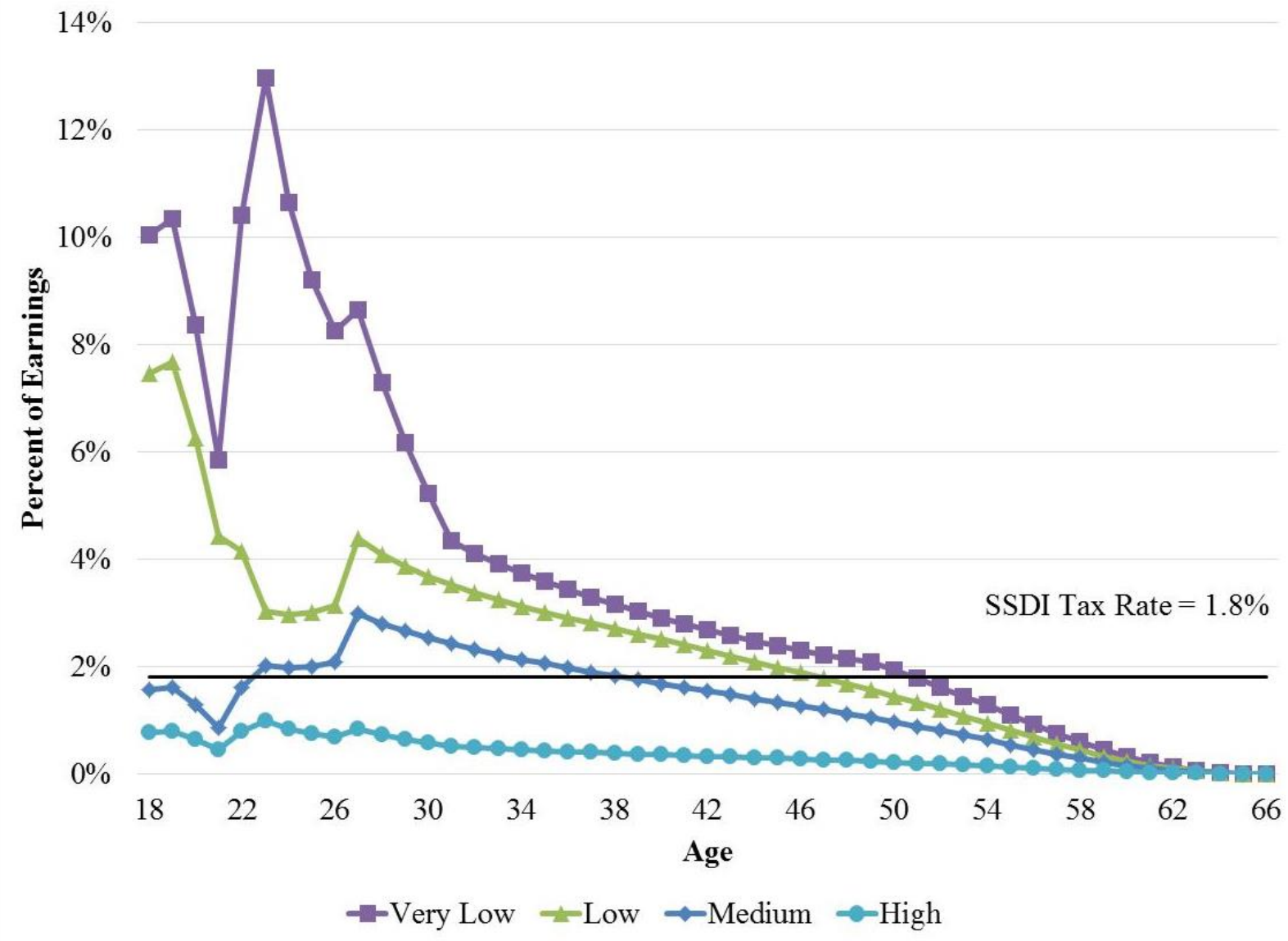

Source: Authors' calculations are based on equation (3), stylized-earnings histories reported in figure 2, and variation in disability incidence rates reported in table 3 . See text for more details. 


\section{Figure 7. Minimum Earnings Extensive Margin Work Incentives by Earnings (Males)}

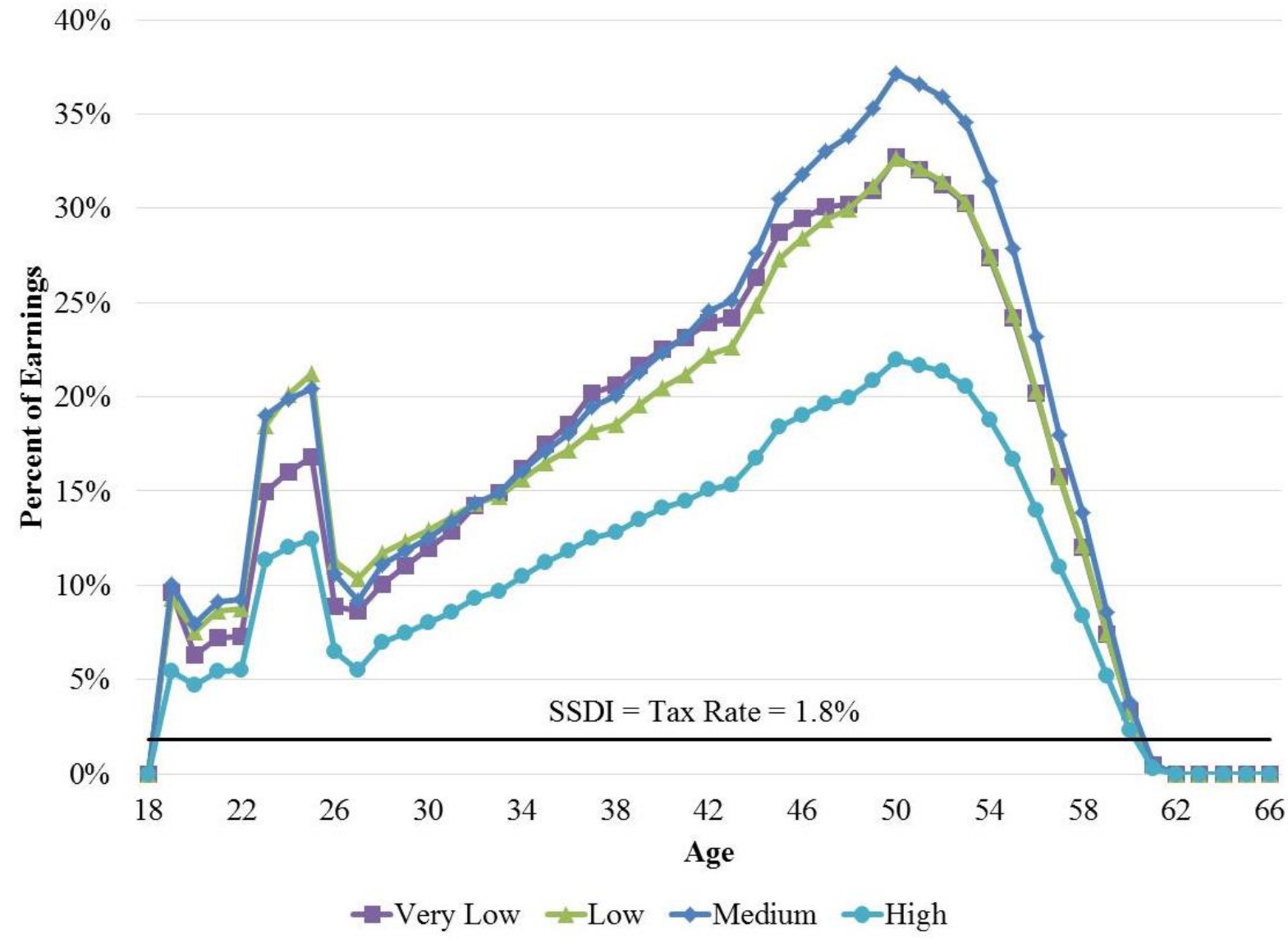

Source: Authors' calculations are based on equation (4), stylized earnings histories reported in figure 2, and variation in disability incidence rates reported in table 3. Workers are assumed to earn the minimum amount required to earn Social Security credits during the additional year of work. See text for more details. 


\section{Figure 8. Full Earnings Extensive Margin Work Incentives by Earnings (Males)}

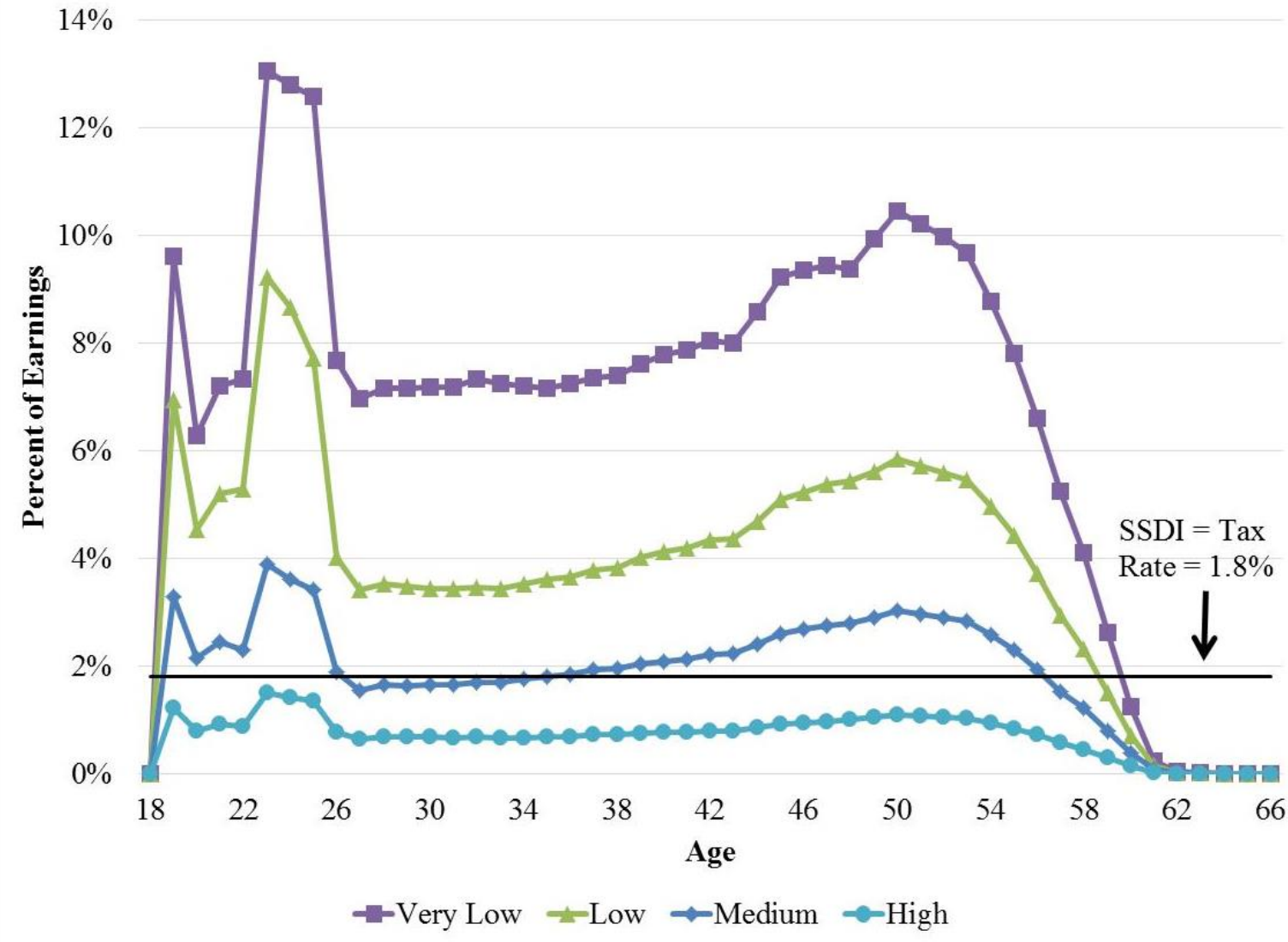

Source: Authors' calculations are based on equation (4), stylized earnings histories reported in figure 2, and variation in disability incidence rates reported in table 3. Workers are assumed to earn the amount shown in corresponding earnings profile in figure 2 during the additional year of work. See text for more details. 